Volume 4 Issue 1(2021) 1-11
Longda Xiokan:

\title{
Pengembangan Media Pembelajaran Kuis Interaktif Pilihan Ganda Bahasa Mandarin Sekolah Menengah Pertama ( SMP )
}

\author{
Septian Adi Setiyo ${ }^{\bowtie}$, Anggraeni Anggraeni, Rina Supriatnaningsih, Ria Riski Marsuki \\ Prodi Pendidikan Bahasa Mandarin, Jurusan Bahasa dan Sastra Asing, Fakultas Bahasa dan Seni, \\ Universitas Negeri Semarang, Indonesia
}

\begin{tabular}{l}
\hline Info Artikel \\
\hline Keywords: \\
media development, \\
interactive quizzes, Chinese \\
multiple-choice questions.
\end{tabular}

\begin{abstract}
Abstrak
Penelitian ini didasari dari hasil observasi dan wawancara kepada mahasiswa PPL yang mengajar Bahasa Mandarin di SMP Tritunggal Semarang pada tahun 2019. Didapatkan data bahwa media pembelajaran yang digunakan oleh guru kurang interaktif dan cenderung satu arah. Hal ini mengakibatkan siswa merasa bosan dan kurang termotivasi dalam pembelajaran yang berdampak kurangnya pemahaman materi oleh siswa dalam pengusaan kosakata bahasa Mandarin. Berdasarkan permasalahan di atas, maka penelitian ini bertujuan 1) menganalisis kebutuhan siswa berbasis Adobe Flash dalam pembelajaran bahasa mandarin; 2) mengembangkan media pembelajaran berbasis Adobe Flash dalam pembelajaran bahasa mandarin.; dan 3) mendeskripsikan validitas ahli dan guru terhadap produk media pembelajaran berbasis Adobe Flash. Hasil penelitian ini adalah guru dan siswa menghendaki media yang berisi beberapa komponen seperti: memuat SK/KD dalam media, materi kosa kata diambil dari HSK, pengantar dalam media menggunakan bahasa Indonesia, dll. Selain itu dalam pengembangan media pembelajaran ini menggunakan Adobe Flash CS6 yang dikembangkan menjadi aplikasi android agar dapat dioperasikan di manapun dan kapanpun. Hasil validasi oleh ahli media menunjukkan bahwa kuis interaktif pilihan ganda bahasa Mandarin mendapat nilai rata - rata 82,53 yang berarti media masuk dalam kategori layak/sesuai dengan skor 3 (rentang nilai 71-85). Hasil uji coba media tersebut menggunakan skala terbatas dengan jumlah responden 10 orang dari peserta didik SMP Tritunggal Semarang menyatakan bahwa media kuis interaktif pilihan ganda bahasa Mandarin yang dikembangkan diminati oleh peserta didik.
\end{abstract}

\section{Abstract}

This research is based on the results of observations and interviews with PPL students who teach Mandarin at SMP Tritunggal Semarang in 2019. Based on a preliminary study, it is found that the learning media used by the teacher is less interactive and tends to be one-way. This results in students feeling bored and less motivated in learning which results in a lack of understanding of the material by students in mastering Mandarin vocabulary. Based on the above problems, then The purpose of this study is 1) to analyze the needs of students based on Adobe Flash in learning Mandarin; 2) developing learning media based on Adobe Flash in Chinese language learning; and 3) describe the validity of experts and teachers for learning media products based on Adobe Flash. The results of this study are that teachers and students want media that contains several components such as: covering SK I $K D$ on the media, vocabulary material taken from HSK, introduction to the media using Indonesian, etc. Besides the development of instructional media using Adobe Flash CS6 developed into an android application so that it can be operated anywhere and anytime. The results of the validation by media experts showed that the Chinese multiple choice interactive quiz got an average score of 82.53 , which means that the media was included in the category according to the score of 3 (range 71-85). The results of the media trial using a limited scale with 10 respondents from Tritunggal Junior High School Semarang students stated that the Chinese multiple choice interactive quiz media developed was of interest to students.

\begin{tabular}{ll}
\hline Alamat korespondensi: & P-ISSN 2528-5734 \\
Gedung B9 Lantai 2 FBS UNNES & E-ISSN 2715-1611 \\
Kampus Sekaran, Gunungpati, Semarang, 50229 & \\
E-mail: septian.adisetivo@gmail.com &
\end{tabular}




\section{PENDAHULUAN}

Di Indonesia saat ini, bahasa Mandarin semakin diminati banyak orang, bahkan di beberapa Negara Asia, Eropa dan USA, bahasa Mandarin menjadi booming. Di Indonesia sendiri khususnya di Jawa Tengah, bahasa Mandarin sudah mulai berkembang pesat, mulai dari les privat, kursus, pelatihan, pelajaran intra atau ekstrakurikuler.

Dari hasil wawancara dengan mahasiswa yang telah PPL mengajar Bahasa Mandarin pada jenjang pendidikan di SMP kota Semarang pada tahun 2019 mendapatkan hasil, media pembelajaran yang digunakan oleh guru kurang interaktif dan cenderung satu arah. Ini mengakibatkan siswa merasa bosan dan kurang termotivasi dalam pembelajaran yang berdampak kurangnya pemahaman materi oleh siswa dalam peningkatan kosakata.

Media berbasis komputer dapat dicapai dengan menggunakan Adobe flash. Adobe flash adalah salah satu Future Splash Animator yang memudahkan pembuatan animasi pada layar komputer dalam menampilkan gambar secara visual dan lebih menarik.

Adobe Flash merupakan salah satu software komputer yang bisa dijadikan sebagai media pembelajaran. Namun, masih banyak guru bahasa mandarin yang belum memanfaatkan Adobe Flash sebagai media pembelajaran. Andi (2010:1) mengemukakan bahwa Adobe Flash yaitu software multimedia unggulan dan populer untuk menambah animasi serta interaktif website. Flash tidak hanya digunakan pada aplikasi web, tetapi juga dikembangkan untuk membuat aplikasi desktop.

Media pembelajaran interaktif berbasis Adobe Flash ini memiliki beberapa elemen di dalamnya, yaitu teks, suara, grafik, animasi, dan aspek interaktif. Perpaduan elemen tersebut menghasilkan sebuah media yang menarik dan dapat menumbuhkan minat siswa untuk belajar. Media pembelajaran kuis interaktif yang berbasis Adobe Flash ini berisi tentang kuis - kuis yang disajikan semenarik mungkin. Bagian akhir media juga dilengkapi dengan evaluasi yang bertujuan memberikan penguatan dan apresiasi bagi siswa.

Maka dari itu, peneliti mencoba untuk mengembangkan media pembelajaran kuis interaktif Bahasa Mandarin yang berbasis Adobe Flash diharapkan dapat mengatasi berbagai permasalahan tentang rendahnya penguasaan kosakata siswa. Dengan demikian, media ini diharapkan juga dapat membantu siswa untuk belajar kosakata sebagai modal untuk mencapai setiap kompetensi dasar yang diajarkan di sekolah.

\section{METODE}

Metode penelitian dalam penelitian ini adalah penelitian dan pengembangan atau Research and Development (R\&D). Penelitian dan pengembangan adalah metode penelitian yang digunakan untuk menghasilkan produk tertentu, dan menguji keefektifan produk tersebut, (Sugiyono 2014:407). Teknik pengumpulan data yang digunakan yaitu observasi, wawancara, dan angket. Menurut Hasan (2006: 24), pengolahan data adalah suatu proses dalam memperoleh data ringkasan atau angka ringkasan dengan menggunakan cara-cara atau rumus-rumus tertentu.

\section{HASIL DAN PEMBAHASAN}

Hasil penelitian yang dipaparkan bab ini meliputi tiga hal, yaitu: (1) hasil analisis kebutuhan pendidik dan peserta didik terhadap pengembangan media pembelajaran kuis interaktif Pilihan Ganda Bahasa Mandarin Sekolah Menengah Pertama bagi peningkatan penguasaan kosakata bahasa Mandarin tingkat dasar (2) prototipe kuis interaktif Pilihan Ganda Bahasa Mandarin yang sesuai dengan analisis kebutuhan (3) analisis validitas ahli terhadap kuis interaktif Pilihan Ganda Bahasa Mandarin.

\section{Hasil Analisis Kebutuhan \\ Hasil Observasi}

Menurut Nawawi dan Martini (1992:74), observasi adalah pengamatan dan pencatatan secara sistematik terhadap unsur-unsur yang 
tampak dalam suatu gejala atau gejala-gejala pada obyek penelitian. Teknik observasi dilakukan untuk mengetahui proses belajar mengajar bahasa Mandarin dan kesulitan pendidik maupun peserta didik dalam pembelajaran. Selain itu juga akan dilakukan penngamatan terhadap permasalahan pembelajaran bahasa Mandarin yang kaitannya dengan media pembelajaran berbasis komputerisasi.

Observasi dilakukan di kelas VIII Faith SMP Tritunggal Semarang. Kegiatan ini dilakukan dengan cara mengamati kegiatan pembelajaran sebelum diberikan produk. Tujuan dilakukannya kegiatan ini untuk memberikan solusi yang tepat melalui perencanaan pengembangan media yang sesuai dengan persoalan di lapangan.

Tabel 1. Hasil Observasi

\begin{tabular}{|c|c|c|c|}
\hline No. & $\begin{array}{c}\text { Aspek yang } \\
\text { diamati }\end{array}$ & Ya & Tidak \\
\hline 1 & $\begin{array}{l}\text { Apakah } \\
\text { pembelajaran } \\
\text { masih } \\
\text { menggunakan } \\
\text { metode } \\
\text { ceramah? }\end{array}$ & $\sqrt{ }$ & \\
\hline 2 & $\begin{array}{l}\text { Apakah siswa } \\
\text { suka bermain } \\
\text { sambil belajar? }\end{array}$ & $\sqrt{ }$ & \\
\hline 3 & $\begin{array}{l}\text { Apakah } \\
\text { pembelajaran } \\
\text { menggunakan } \\
\text { media? }\end{array}$ & $\sqrt{ }$ & \\
\hline 4 & $\begin{array}{l}\text { Apakah media } \\
\text { yang digunakan } \\
\text { dapat } \\
\text { memotivasi } \\
\text { siswa? }\end{array}$ & & $\sqrt{ }$ \\
\hline 5 & $\begin{array}{l}\text { Apakah media } \\
\text { yang digunakan } \\
\text { dapat } \\
\text { memudahkan } \\
\text { siswa dalam } \\
\text { menguasai }\end{array}$ & $\sqrt{ }$ & \\
\hline
\end{tabular}

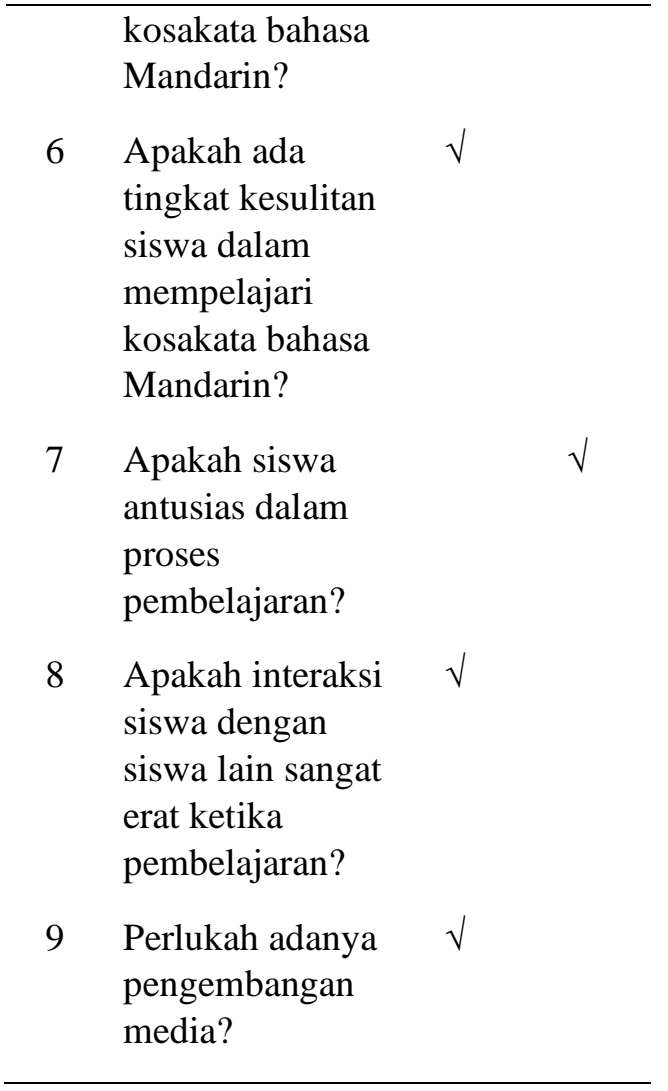

Berdasarkan tabel tersebut dapat dideskripsikan bahwa pembelajaran kosakata bahasa Mandarin di dalam kelas sudah efektif, namun perlu untuk ditingkatkan. Hal ini disebabkan kurangnya motivasi dan antusias peserta didik dalam menghafalkan kosakata walaupun pendidik sudah menggunakan metode mengajar yang baik

\section{Hasil Angket Kebutuhan Peserta Didik}

Angket untuk peserta didik dirancang untuk mengumpulkan data yang berkaitan dengan kebutuhan peserta didik terhadap pengembangan media kuis teraktif pilihan ganda bahasa Mandarin. Peneliti mengambil sampel dari siswa - siswi kelas VIII Faith SMP Tritunggal Semarang yang sedang

Berdasarkan tabel tersebut dapat dideskripsikan bahwa pembelajaran kosakata bahasa Mandarin di dalam kelas sudah efektif, namun perlu untuk ditingkatkan. Hal ini disebabkan kurangnya motivasi dan antusias peserta didik dalam menghafalkan kosakata walaupun pendidik sudah menggunakan metode mengajar yang baik. 


\section{Hasil Angket Kebutuhan Peserta Didik}

Angket untuk peserta didik dirancang untuk mengumpulkan data yang berkaitan dengan kebutuhan peserta didik terhadap pengembangan media kuis teraktif pilihan ganda bahasa Mandarin. Peneliti mengambil sampel dari siswa - siswi kelas VIII Faith SMP Tritunggal Semarang yang sedang belajar bahasa Mandarin tingkat dasar sebanyak 26 siswa. Hasil kesimpulan dari angket analisis kebutuhan siswa yaitu :

Untuk tingkat kesulitan dalam belajar bahasa Mandarin beberapa peserta didik tidak mengalami kesulitan dalam mempelajari kosakata bahasa Mandarin. Namun, sebagian peserta didik ada yang masih kesulitan dalam mempelajari kosakata bahasa Mandarin.

Ketersediaan media untuk belajar kosakata bahasa Mandarin cukup memadai, namun perlu ditingkatkan agar peserta didik termotivasi dan tidak merasa bosan dalam belajar bahasa Mandarin. Begitu juga untuk sarana media pembelajaran yang masih kurang maksimal digunakan, maka dari itu peneliti akan mencoba untuk memaksimalkan sarana media pembelajaran untuk membantu peningkatan kosakata bahasa Mandarin.

Sebagian peserta didik setuju dengan adanya media kuis interaktif pilihan ganda bahasa Mandarin. Selain untuk mempelajari kosakata, media tersebut menarik minat peserta didik untuk aktif belajar, dikarenakan peserta didik dapat bermain sambil belajar. Materi yang digunakan media kuis interaktif mengacu pada buku HSK 2 tingkat dasar di sekolah tersebut.

Dalam pembuatan kuis interaktif pilihan ganda bahasa Mandarin, sebagian peserta didik memilih jumlah soalnya adalah 50 soal. Waktu yang dibutuhkan untuk mengerjakan satu soal peserta didik memilih waktu yang standar, namun bergantung pada tingkat kesulitan pada soal di dalam kuis tersebut. Peserta didik menyarankan untuk adanya petunjuk penggunaan agar memahami perintah dalam kuis tersebut.

Dalam pembuatan kuis interaktif pilihan ganda bahasa Mandarin, sebagian besar peserta didik memilih font (我爱你KaiTi) dengan warna yang bagus dan jelas ketika dibaca. Sebagian besar peserta didik juga setuju jika adanya tampilan awal di dalam kuis dengan warna tersier agar lebih menarik, serta penambahan backsound music di dalam media.

Sebagian besar peserta didik memerlukan adanya gambar ilustrasi yang sesuai agar mudah memahami kosakata yang diberikan. Peserta didik juga setuju jika resolusi media dibuat dengan versi yang cukup tinggi, agar media dapat digunakan untuk seluruh versi smarthphone android.

\section{Hasil Wawancara Peserta Didik}

Wawancara yang dilakukan dalam penelitian ini adalah dengan pendidik bahasa Mandarin SMP Tritunggal Semarang untuk memperoleh data mengenai kesulitan mengajar bahasa Mandarin tingkat dasar dan ketersediaan media pembelajaran yang kreatif dan inovatif.

Tabel 2. Hasil Wawancara dengan Pendidik

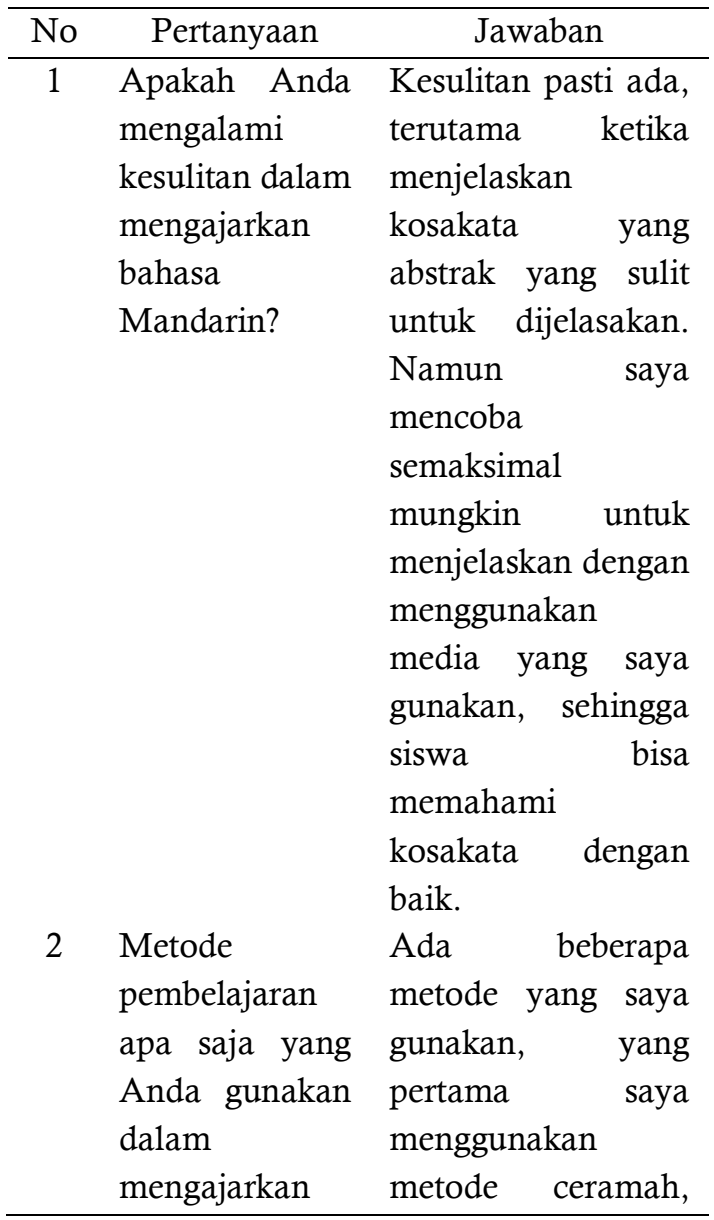


Septian Adi Setiyo dkk. / Longda Xiaokan: Journal of Mandarin Learning and Teaching 4 (1) (2021)

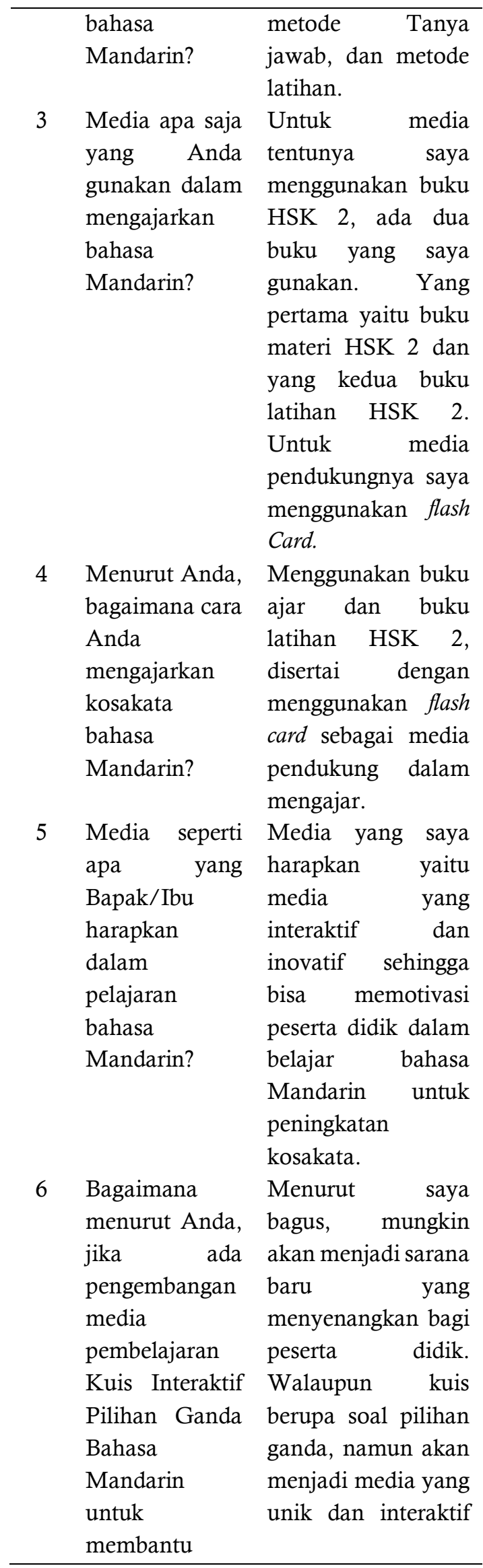

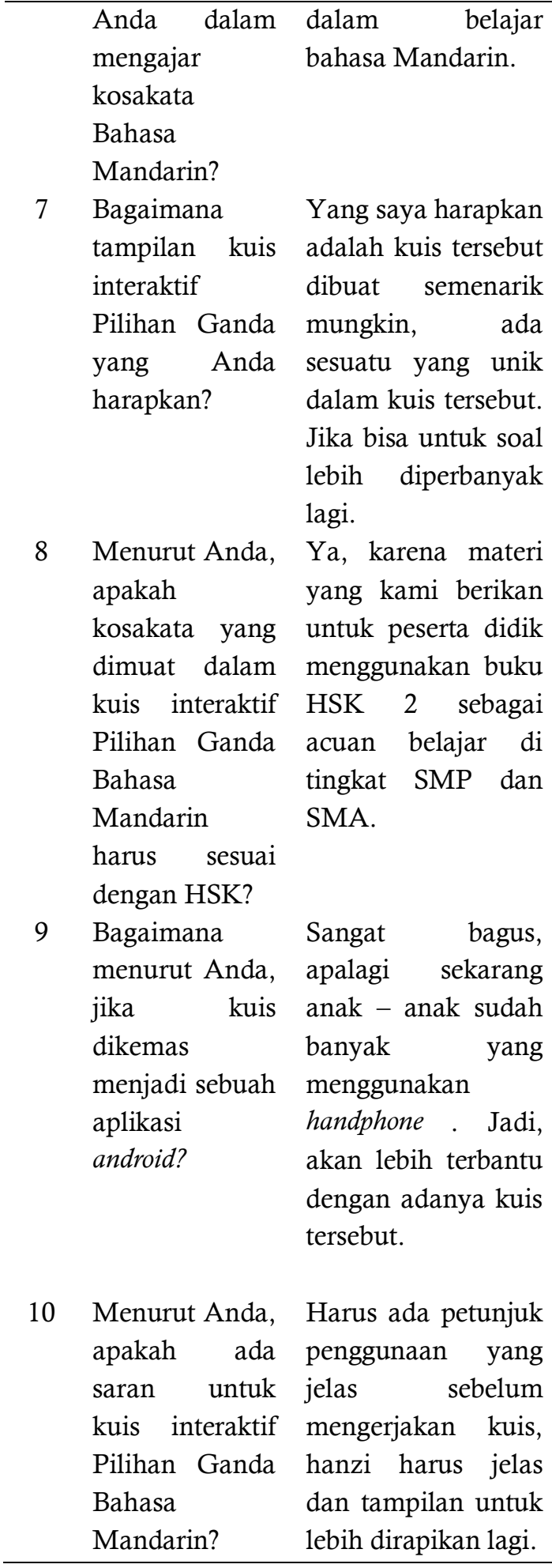

Kesimpulan dari hasil wawancara dengan pendidik, dapat dideskripsikan bahwa pendidik membutuhkan media tambahan dalam mengajar khususnya mengajarkan kosakata yang disesuaikan dengan standar kompetensi yang telah ditentukan. Pendidik mengharapkan media 
kuis interaktif yang dikembangkan memuat petunjuk penggunaan, materi yang sesuai, kosakata yang sesuai, dan animasi yang mendukung.

Prototipe Pengembangan Media Pembelajaran Kuis Interaktif Pilihan Ganda Bahasa Mandarin

Pengembangan kuis interaktif pilihan ganda bahasa Mandarin telah disesuaikan dengan analisis kebutuhan yang telah dilakukan. Meskipun dalam pembuatannya ada beberapa hal yang dipertimbangkan dan disesuaikan, akan tetapi hasil analisis kebutuhan tetap dijadikan acuan dalam pengembangan kuis interaktif.

\section{Tampilan Awal Pembukaan}

Halaman pembuka diawali dengan tampilan full screen dan background berwarna merah dengan pemandangan siluet. Yang terdiri dari logo Mandarin Interactive Media yang dikelilingi lingkaran berputar dan tombol "START".

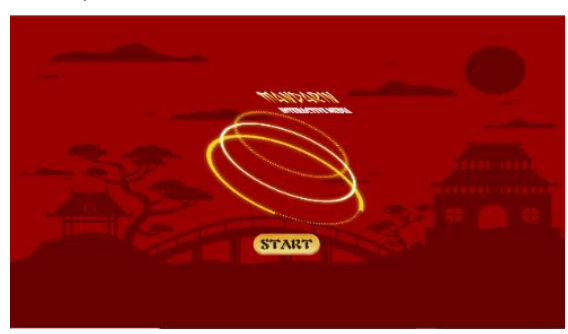

Gambar 1. Tampilan Awal

\section{Tampilan Menu Awal}

Pada menu utama terdapat teks "Selamat Datang", tombol, Home, tombol Kompetensi Dasar, tombol Tujuan, tombol Sumber Materi, tombol Petunjuk Kuis, tombol Kuis, tombol Profil, tombol Keluar, tombol on atau off music, Jam Digital, dan teks Mandarin Interactive Media.

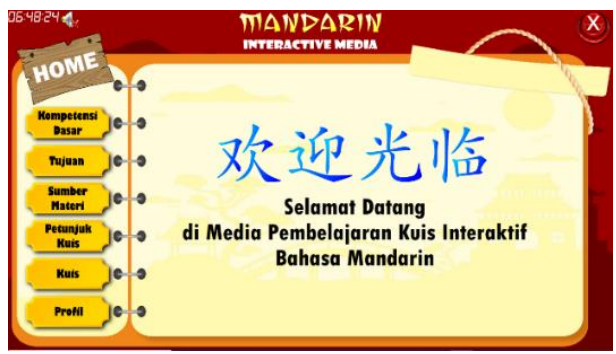

Gambar 2. Tampilan Menu Utama

\section{Tampilan Menu Kompetensi Dasar}

Halaman Kompetensi Dasar muncul apabila tombol "Kompetensi Dasar" yang terdapat pada halaman menu utama diklik. Halaman Kompetensi berisi kompetensi yang harus dicapai meliputi: Kompetensi dasar, dan Indikator.

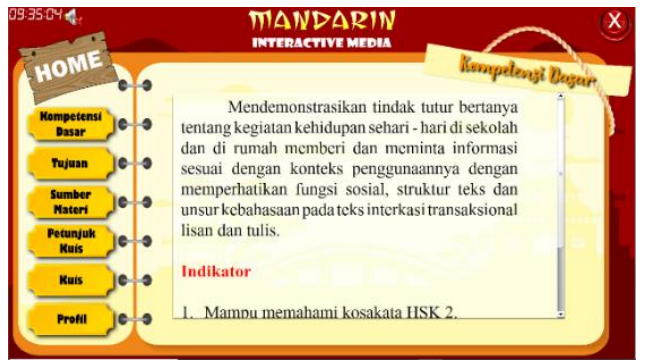

Gambar 3. Tampilan Menu Kompetensi Dasar

\section{Tampilan Menu Tujuan}

Halaman Tujuan muncul apabila tombol "Tujuan" yang terdapat pada halaman menu utama diklik. Halaman tujuan berisi tujuan dari peneliti tentang pengembangan media pembelajaran.

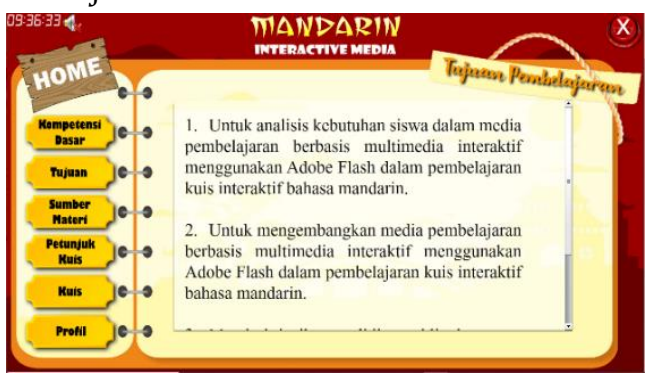

Gambar 4. Tampilan Menu Tujuan

\section{Tampilan Sumber Materi}

Halaman Sumber Materi muncul apabila tombol "Sumber Materi" yang terdapat pada halaman menu utama diklik. Halaman tujuan berisi sumber materi dari pembuatan kuis interaktif.

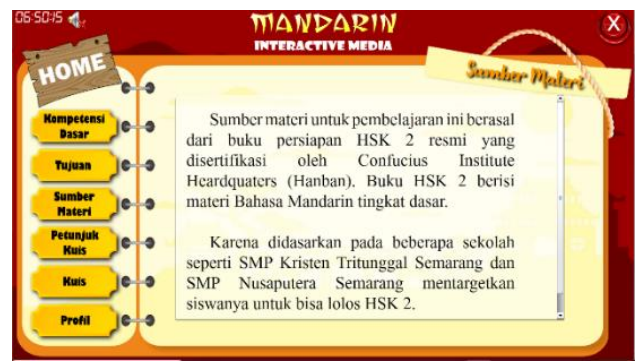

Gambar 5. Tampilan Sumber Materi 


\section{Tampilan Menu Petunjuk Pengguna}

Halaman petunjuk penggunaan muncul apabila tombol "Petunjuk Penggunaan" yang terdapat pada halaman menu utama diklik. Halaman petunjuk penggunaan berisi langkah langkah dalam mengoperasikan media pembelajaran dari mulai menjalankan media pembelajaran sampai dengan mengoperasikan isi dari media pembelajaran.

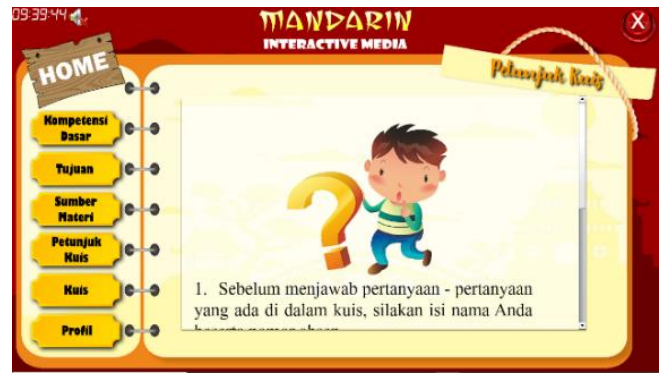

Gambar 6. Tampilan Menu Petunjuk Pengguna

\section{Tampilan Awal Kuis}

Pada tampilan awal kuis, sebelum menjawab soal - soal kuis harus mengisi nama dan nomor absen terlebih dahulu. Setelah mengisi nama dan nomor absen selesai, kemudian klik tombol "Mulai".

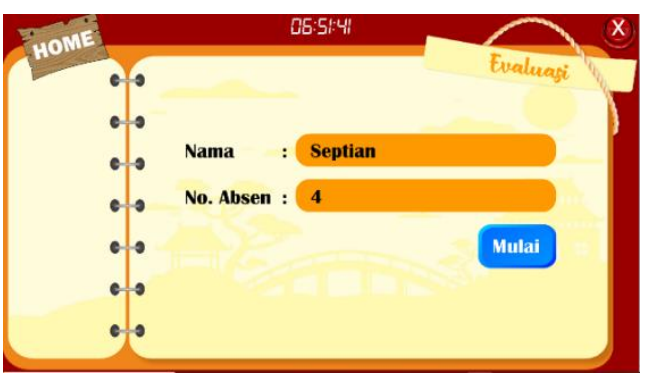

Gambar 7. Tampilan Awal Kuis

\section{Tampilan Kuis Soal Pilihan Ganda}

Tampilan soal pilihan ganda berisi tombol pilihan jawaban A, B, C, dan D. Untuk memilih jawaban dengan cara klik salah satu tombol jawaban. Kemudian akan muncul poin sementara sesuai jawaban yang dipilih Benar atau Salah. Jika jawaban Benar akan mendapat 1 (satu) poin per soal. Jika jawaban Salah tidak mendapatkan poin. Setelah menjawab soal, lalu klik tombol panah untuk ke soal selanjutnya.

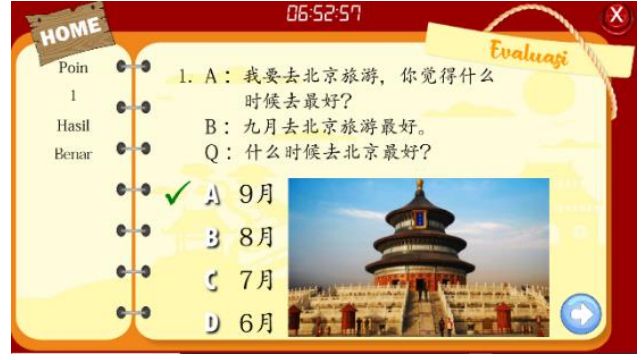

Gambar 8. Tampilan Kuis SoalPilihan Ganda

\section{Tampilan Hasil Kuis Pilihan Ganda}

Setelah selesai menjawab semua soal kuis pilihan ganda, maka akan terlihat skor akhir dari poin jawaban Benar dikali banyaknya soal.

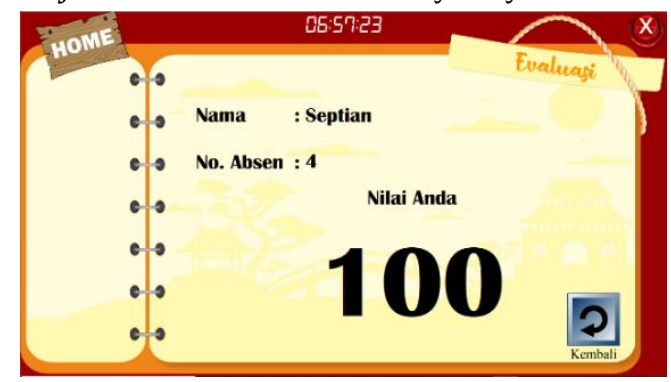

Gambar 9 Tampilan Hasil Kuis Pilihan Ganda

\section{Tampilan Menu Profil Pengembangan}

Tampilan pada halaman profil berisi foto dan identitas pengembang media pembelajaran. Halaman tersebut apabila tombol "Profil" pada halaman menu utama diklik.

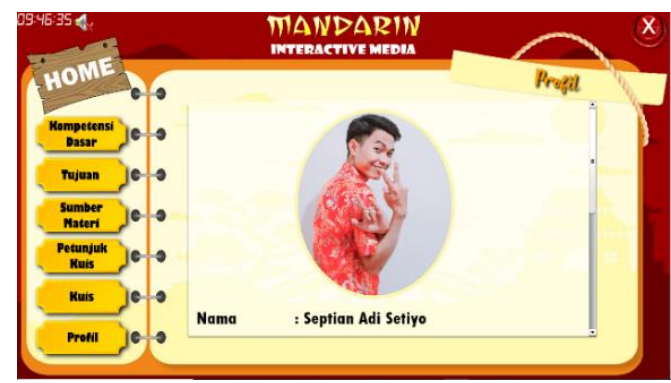

Gambar 10. Tampilan Menu Profil

Pengembangan

\section{Hasil Validasi dan Saran Perbaikan terhadap}

Prototipe Pengembangan Media Pembelajaran Kuis Interaktif Pilihan Ganda Bahasa Mandarin

Setelah menyelesaikan penyusunan prototype kuis interaktif Pilihan Ganda bahasa Mandarin, maka langkah selanjutnya adalah melakukan validasi terhadap media kuis tersebut. Menurut Emzir (2011:273), validasi produk 
dapat dilakukan dengan meminta beberapa orang pakar dalam bidangnya untuk menilai desain produk yang kita buat dengan forum diskusi, denga terlebih dahulu peneliti mempresentasikan desain produk yang dibuatnya. Validasi dilakukan oleh dua ahli, yaitu ahli materi bahasa Mandarin dan ahli media dalam bidang desain. Adapun kategori untuk penilaian prototype kuis interaktif Pilihan Ganda Bahasa Mandarin adalah sebagai berikut:

Tabel 3. Kategori Validasi Prototipe

\begin{tabular}{|c|c|c|}
\hline Skor & $\begin{array}{l}\text { Rentang } \\
\text { Nilai }\end{array}$ & Kategori \\
\hline 4 & $86-100$ & $\begin{array}{c}\text { Sangat } \\
\text { layak/sangat sesuai }\end{array}$ \\
\hline 3 & $71-85$ & Layak/sesuai \\
\hline 2 & $56-70$ & $\begin{array}{c}\text { Tidak layak/tidak } \\
\text { sesuai }\end{array}$ \\
\hline 1 & $41-55$ & $\begin{array}{c}\text { Sangat tidak } \\
\text { layak/sangat tidak } \\
\text { sesuai }\end{array}$ \\
\hline
\end{tabular}

\section{Validasi Ahli Materi}

Validasi dilakukan oleh ahli materi bahasa Mandarin Universitas Negeri Semarang, Ibu Anggraeni, S.T.,MTCSOL. Valiadi oleh ahli materi meliputi empat aspek, yaitu (1) aspek kelayakan isi, (2) aspek kelayakan sajian, (3) aspek kontekstual, dan (4) aspek kelayakan bahasa.

Tabel 4. Rekapitulasi Validasi Pengembangan Media Pembelajaran Kuis Interaktif Pilihan

\begin{tabular}{ccc}
\multicolumn{3}{c}{ Ganda Bahasa Mandarin } \\
\hline Aspek & Indikator Penilaian & Nilai \\
\hline Isi & $\begin{array}{c}\text { Kesesuaian materi } \\
\text { yang disajikan } \\
\text { dalam media }\end{array}$ & \\
& pembelajaran \\
& dengan kompetensi \\
dasar dan HSK & \\
Keakuratan Materi & 83,5 \\
& Kemutakhiran & 83,5 \\
$\quad$ Materi \\
Mendorong rasa \\
keingintahuan \\
Teknik Penyajian
\end{tabular}

\begin{tabular}{|c|c|c|}
\hline \multirow{6}{*}{$\begin{array}{l}\text { Kelayakan } \\
\text { Penyajian }\end{array}$} & Penyajian Materi & 85 \\
\hline & Pembelajaran & \\
\hline & Pendukung & 82 \\
\hline & Penyajian & \\
\hline & Koherensi dan & 85 \\
\hline & $\begin{array}{l}\text { keruntutan alur } \\
\text { pikir }\end{array}$ & \\
\hline \multirow[t]{6}{*}{ Kontekstual } & Hakikat & 85 \\
\hline & Kontekstual & \\
\hline & Komponen & 85 \\
\hline & Kontekstual & \\
\hline & (Konstruktivisme, & \\
\hline & $\begin{array}{l}\text { Inquiry, Question } \\
\text { dan Modelling) }\end{array}$ & \\
\hline \multirow{4}{*}{$\begin{array}{c}\text { Kelayakan } \\
\text { Bahasa }\end{array}$} & Lugas & 82 \\
\hline & Komunikatif & 85 \\
\hline & $\begin{array}{l}\text { Kesesuaian dengan } \\
\text { perkembangan } \\
\text { peserta didik }\end{array}$ & 85 \\
\hline & Penggunaan Istilah & 85 \\
\hline \multicolumn{2}{|c|}{ Rata-rata keseluruhan } & 84,4 \\
\hline
\end{tabular}

Berdasarkan tabel di atas dapat disimpulkan bahwa, media Kuis Interaktif Pilihan Ganda Bahasa Mandarin mendapatkan nilai rata-rata dari ahli materi secara keseluruhan yaitu 84,4 yang berarti media masuk dalam kategori sesuai/layak sesuai dengan skor 3 (rentang nilai 71-85). Hal ini berarti media Kuis Interaktif Pilihan Ganda Bahasa Mandarin dinyatakan sesuai/layak digunakan baik dari aspek kelayakan isi, aspek kelayakan penyajian, aspek kontekstual, dan aspek kelayakan bahasa dengan beberapa perbaikan agar media dapat menjadi lebih maksimal untuk digunakan.

\section{Validasi Ahli Media}

Validasi desain produk media dilakukan oleh Bapak Wandah Wibawanto, S.Sn., M.Ds. selaku dosen Desain Komunikasi Visual Universitas Negeri Semarang. Validasi oleh ahli media meliputi 3 aspek, yaitu (1) aspek perangkat lunak, (2) aspek tampilan, dan (3) aspek visual.

Tabel 5. Rekapitulasi Validasi Media

Pembelajaran Kuis Interaktif Pilihan Ganda Bahasa Mandarin 


\begin{tabular}{|c|c|c|}
\hline Aspek & Butir Penilaian & Nilai \\
\hline Perangkat & Maintainable & 86 \\
\hline \multirow[t]{5}{*}{ Lunak } & Usability & 80 \\
\hline & Kompabilitas & 86 \\
\hline & Kejelasan & \\
\hline & dokumentasi & 80 \\
\hline & program media & \\
\hline \multirow[t]{11}{*}{ Tampilan } & Ketepatan & \\
\hline & $\begin{array}{c}\text { pemilihan warna } \\
\text { background }\end{array}$ & 86 \\
\hline & Komposisi dan & \\
\hline & $\begin{array}{l}\text { kombinasi warna } \\
\text { template }\end{array}$ & 80 \\
\hline & Keserasian warna & \\
\hline & $\begin{array}{l}\text { background } \\
\text { dengan tulisan }\end{array}$ & 80 \\
\hline & $\begin{array}{l}\text { Ketepatan ukuran } \\
\text { gambar dengan } \\
\text { komposisi ukuran } \\
\text { tulisan }\end{array}$ & 86 \\
\hline & $\begin{array}{c}\text { Ketepatan } \\
\text { pemilihan latar } \\
\text { musik }\end{array}$ & 88 \\
\hline & Ketepatan tombol & \\
\hline & $\begin{array}{c}\text { dan } \\
\text { penempatannya }\end{array}$ & 80 \\
\hline & $\begin{array}{l}\text { Sederhana dan } \\
\text { memikat }\end{array}$ & 80 \\
\hline \multirow[t]{6}{*}{ Visual } & Kejelasan petunjuk & \\
\hline & $\begin{array}{c}\text { penggunaan } \\
\text { program }\end{array}$ & 86 \\
\hline & $\begin{array}{l}\text { Kemudahan } \\
\text { navigasi pada }\end{array}$ & 80 \\
\hline & setiap layer/scene & \\
\hline & $\begin{array}{c}\text { Kemudahan } \\
\text { penggunaan } \\
\text { tombol }\end{array}$ & 80 \\
\hline & Sistematika kuis & 81 \\
\hline \multicolumn{2}{|c|}{ Rata - rata keseluruhan } & 82,53 \\
\hline
\end{tabular}

Berdasarkan tabel di atas dapat disimpulkan bahwa, media kuis interaktif pilihan ganda bahasa Mandarin mendapatkan nilai rata - rata dari ahli media secara keseluruhan yaitu 82,53 yang masuk dalam kategori sesuai/layak dengan skor 3 (rentang nilai 71-85). Hal ini berarti media kuis interaktif pilihan ganda bahasa mandarin layak digunakan baik dari aspek rekayasa perangkat lunak, aspek tampilan dan aspek visual dengan adanya revisi.

\section{Perbaikan Terhadap Desain Produk Media Kuis Interaktif Pilihan Ganda Bahasa Mandarin}

Desain prototipe media yang telah divalidasi oleh ahli materi dan ahli media selanjutnya dilakukan perbaikan sesuai dengan saran - saran maupun masukan para ahli. Berdasarkan saran dan masukan ahli, terdapat perbaikan dalam aspek kelayakan bahasa. Ahli materi menyarankan agar untuk memperbaiki bagian kalimat pertanyaan yang kurang tepat, supaya peserta didik mudah memahami setiap kalimat pertanyaan dengan baik. Ahli media menyarankan untuk menambahkan beberapa fitur, yaitu penambahan fitur kosakata beserta audio pelafalan supaya tidak monoton dan penambahan fitur bahasa lain ( bahasa Indonesia ), dan perbaikan peletakan tombol agar lebih konsisten.

\section{Perbaikan Aspek Kelayakan Bahasa}

九月的北京天气不冷也不热。 Sebelum direvisi

九月北京天气不冷也不热。 Setelah direvisi

\section{Gambar 11. Perbaikan Kalimat Pertanyaan}

Tampilan pada gambar di atas adalah memperbaiki kaliamat yang kurang tepat, yaitu menghilangkan kata “的” pada kalimat tersebut. Perbaikan disesuaikan dengan saran ahli materi.

\section{Perbaikan pada Aspek Rekayasa Perangkat} Lunak 
Septian Adi Setiyo dkk. / Longda Xiaokan: Journal of Mandarin Learning and Teaching 4 (1) (2021)

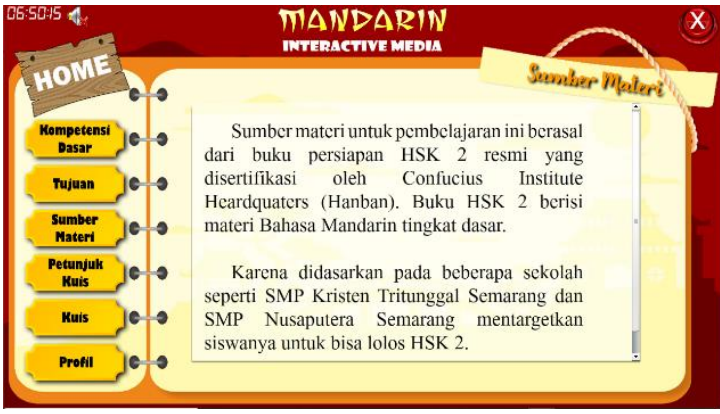

Sebelum revisi

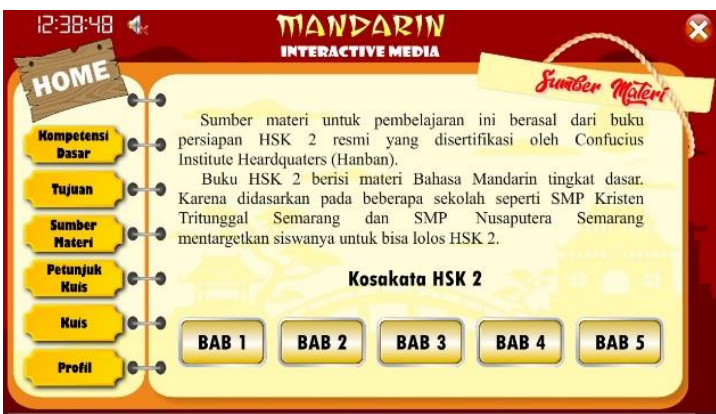

Setelah revisi

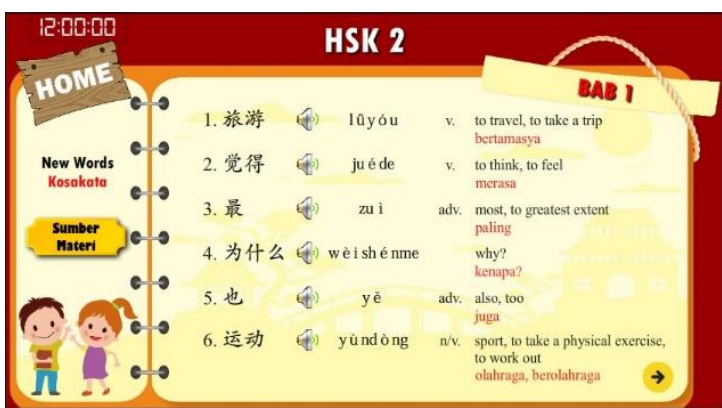

Sebelum revisi

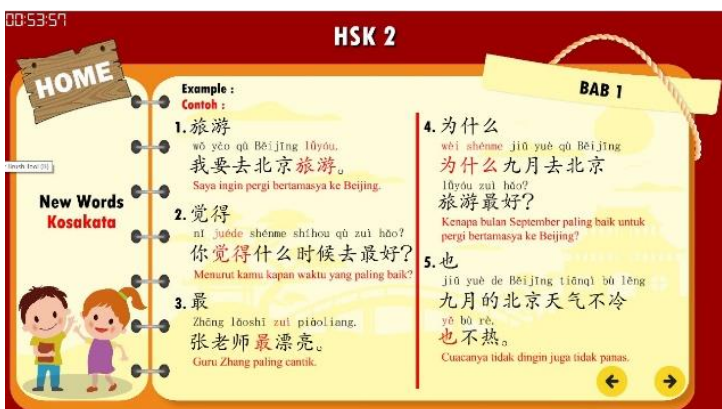

Setelah revisi

Gambar 12 Perbaikan Penambahan Fitur Media

Tampilan pada gambar di atas adalah menambahkan fitur kosakata beserta audio pelafalannya, penambahan fitur bahasa lain dan contoh kalimatnya. Perbaikan disesuaikan dengan saran dari ahli media.

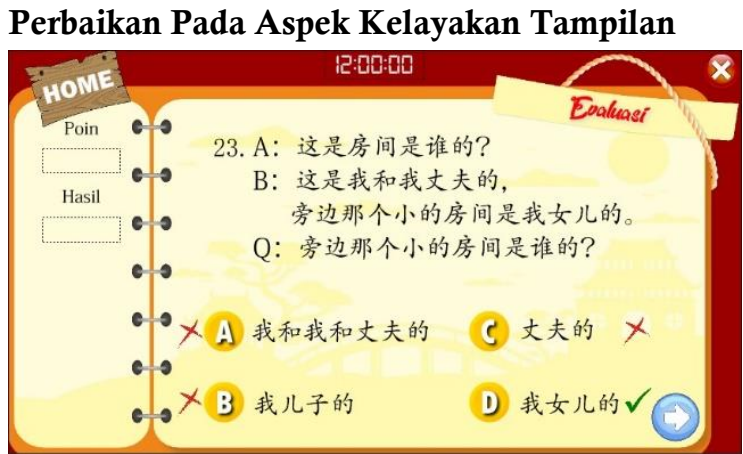

Sebelum direvisi

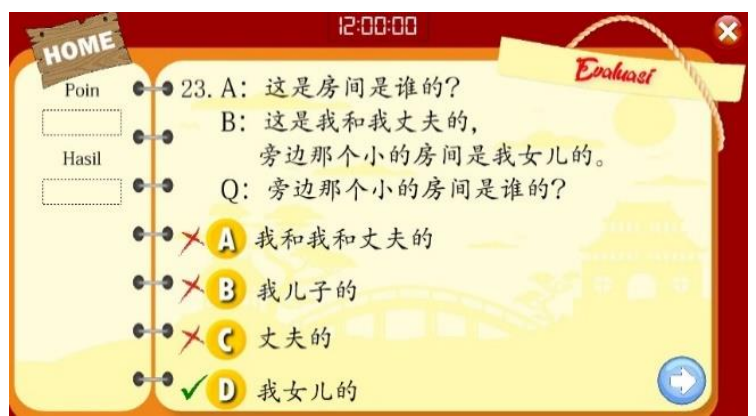

Setelah direvisi

Gambar 13. Perbaikan Peletakan Tombol

Tampilan pada gambar di atas adalah memperbaiki peletakkan tombol agar lebih konsisten. Perbaikan disesuaikan dengan saran dari ahli media.

\section{SIMPULAN}

Berdasarkan pada hasil analisis kebutuhan pendidik dan peserta didik terhadap media Kuis Interaktif Pilihan Ganda Bahasa Mandarin berbasis Adobe Flash CS6 menunjukkan hasil guru dan siswa menghendaki media yang berisi beberapa komponen sebagai berikut: (1) SK dan $\mathrm{KD}$ yang memuat tujuan pembelajaran yang ingin dicapai melalui bantuan media Kuis Interaktif Pilihan Ganda Bahasa Mandarin, (2) tujuan media kuis interaktif yaitu untuk meningkatkan penguasaan kosakta bahasa Mandarin (3) kosakata diambil dari materi bahasa Mandarin tingkat dasar yaitu HSK 2, (4) media menggunakan bahasa Indonesia sebagai pengantar, (5) evaluasi kuis berisi latihan soal dari bab 1 sampai bab 5 dari buku materi HSK 2. (6) dan profil pengembang media kuis interaktif pilihan ganda bahasa Mandarin berbasis Adobe Flash CS6 . 
Pengembangan media kuis interaktif pilihan ganda bahasa Mandarin dibuat menggunakan aplikasi berbasis Adobe Flash CS6 yang mana sebelumnya hanya dapat dioperasikan laptop atau komputer, kemudian peneliti mengemas media dalam bentuk sebuah aplikasi android agar peserta didik juga dapat mengoperasikan media tersebut, sehingga media dapat dioperasikan di manapun dan kapanpun.

Hasil validasi oleh ahli materi menunjukkan bahwa media kuis interaktif pilihan ganda bahasa Mandarin mendapat nilai rata - rata 84,4 yang berarti media masuk dalam kategori layak/sesuai dengan skor 3 (rentang nilai $71-85$ ). Adapun saran perbaikan dari ahli materi yaitu memperbaiki bagian kalimat pertanyaan yang kurang tepat, supaya peserta didik mudah memahami setiap kalimat pertanyaan dengan baik. Hasil validasi oleh ahli media menunjukkan bahwa kuis interaktif pilihan ganda bahasa Mandarin mendapat nilai rata - rata 82,53 yang berarti media masuk dalam kategori layak/sesuai dengan skor 3 (rentang nilai 71-85). Adapun saran perbaikan dari ahli media yaitu sebagai berikut : (1) Penambahan fitur kosakata beserta audio pelafalan supaya tidak monoton dan penambahan fitur bahasa lain ( bahasa Indonesia ), (2) memperbaiki peletakkan tombol agar lebih konsisten.

\section{DAFTAR PUSTAKA}

Andi Sunyoto. 2010. "Adobe Flash $+\mathrm{XML}=$ Rich Multimedia Application", Andi Offset, Yogyakarta.

Emzir. 2011.Metodologi Penelitian Kualitatif Analisis Data. Jakarta: Rajawali Pers

Hasan, Iqbal. 2006. Analisis Data Penelitian dengan Statistik. Jakarta:Bumi Aksara

Nawawi, Hadari dan M. Martini Hadari. 1992. Instrumen Penelitian Bidang Sosial. Yogyakarta: Gadjah Mada University Press.

Sugiyono. 2014. Metode Penelitian Pendidikan Pendekatan Kuantitatif, Kualitatif, dan R\&D. Bandung: Alfabeta. 